\title{
ANALYSIS OF INFILL FRAME WITH GAP ELEMENTS USING FINITE ELEMENT APPROACH
}

\author{
V. Lavanya ${ }^{1}$, B.Kavya, P. Anuradha ${ }^{3}$, N. Murali Krishna ${ }^{4}$ \\ ${ }^{1}$ Post Graduate Student, Department of Civil Engineering, Osmania University, Telangana, India \\ ${ }^{2}$ Under Graduate Student, Department of Civil Engineering, Osmania University, Telangana, India \\ ${ }^{3}$ Research Scholar, Assistant Professor, Department of Civil Engineering, Osmania University, Telangana, India \\ ${ }^{4}$ Professor, Department of Civil Engineering, Osmania University, Telangana, India
}

\begin{abstract}
The rapid urbanisation demands the need of high raised buildings which are always vulnerable to the lateral loads caused due to natural calamities. These lateral loads affect the stability of the structure. The shear walls, which are provided to resist the lateral forces, are not desirable from utility point of view as they come in the way of vehicular movement in the parking floor. In this context the contribution available from wall panels, called infill walls is considered. In this paper, the contribution offered from infill walls to the lateral strength of the building is evaluated using FEM approach. In this approach the infill wall contribution is replaced with two diagonal struts joining the opposite corners of the frame. The general purpose Finite Element package MSC NASTRAN is used to evaluate the infill contribution. Frames with different aspect ratios of span to height with and without wall opening are taken up for the study. On obtaining the strain energy of the infill frame, the infill wall is replaced by equivalent diagonal struts joining the opposite corners of the frame of width to match in strain energy. To make the application more widely applicable, the data obtained from different case studies has been tabulated to train a neural net. The train neural net is expected to offer the width of equivalent strut once the necessary input data is fed. The utility of the study is improved as more data is added.. Later the effect of crack widening in the infill panel was shown by the introduction of gap elements wherever the tensile stress was found more than the permissible value. The failure pattern when a horizontal load, vertical load and rotation each applied in turn at each corner of the infill panel with gap elements is studied
\end{abstract}

Keywords: Infill, Infill frame, Equivalent Strut, Gap Elements, Diagonal strut

\section{INTRODUCTION}

The increased urbanisation is reflected by large number of high-raised buildings. The need for high-raised structures arises due to lack of space, high cost of land and architectural requirements. The high raised structures are vulnerable to loads generated due to natural calamities like earthquakes, typhoons and tsunamis. In addition, there can be calamities due to human induced causes like blasts. The effects described above cause very large amount of lateral forces due to which the high-raised structures are subjected to large over turning moments and shear forces at the base. In the past, the buildings were designed only for vertical loads, caused due to gravity loads and imposed loads. But as the frequency of occurrence of calamities are on rise resulting in recent times, huge losses caused to both property and life, the governmental agencies have been revising the structural design codes frequently to withstand all kinds of calamities.

To counter the effect of lateral forces, the shear walls are provided in building structures. The specifications for shear walls have already been developed in the design codes. But the large sized shear walls provided in buildings always become an obstacle for vehicle movement in the parking lots. This apart, the other functional utilities of the building are also partly affected due to the presence of shear walls emanating from basement floor to the topmost floor. In this backdrop, the infill contribution to resist lateral loads has come in very handy and the investigation is progressing in this direction.

Wall panels are integral part of any beam column framing to perform the functionality of a building. These wall panels though made up of masonry, a relatively weaker material in comparison to concrete, offer substantial lateral resistance to lateral loads by virtue of its larger sectional area. Neither are the column members designed for resisting lateral loads. The wall panel bounded by the frame members consisting of beams and columns all around is called infill wall. The reinforced concrete frame inclusive of infill wall is called infill frame. Here, the integral action of the wall and frame is to be considered to evaluate the horizontal load that can be taken up by the infill wall panel. The general purpose finite element package MSC NASTRAN is used for the FEM analysis.

With this large data of information, it is felt appropriate to develop a neural network to evaluate the width of equivalent struts. Since the input variables and output variables here are of continuous type, the BOPN Neural Net paradigm suits better for the present problem. The list of input variables include the span, the storey height, the area of the door opening, the area of window opening, the thickness of wall, grade of concrete, the linear/non-linear elasticity of concrete 
and the output variables include the width of the equivalent strut. A five layered neural net architecture is selected to simulate the present problem. The $\mathbf{C}^{++}$source code listing for the BOPN neural net is developed to train the data. After successful simulation of training patterns, we started getting results to our satisfaction. However, at present the error in output results that is resulted from the net is a little high, since the numbers of training patterns are too few.

Later the effect of crack widening in the infill panel was shown by the introduction of gap elements wherever the tensile stress was found more than the permissible value. The failure pattern when a horizontal load, vertical load and rotation each applied in turn at each corner of the infill panel with gap elements is studied

\section{LITERATURE REVIEW}

Smith (1), who had adopted the equivalent diagonal strut concept, had assumed the strut thickness to be the same as that of the infill. He had applied finite difference method to biharmonic equations (expressed in terms of Airy's stress function) to obtain expressions for the Airy's stress function. Using Airy's stress function then, he could determine the stresses in the infill. The subsequent strains in the infill were determined using the stress-strain plots. The diagonal stiffness of the infill was derived from thereon. The finite difference methods adopted by him were considered to be superior numerical techniques during times when finite element concepts were still not clear to many. Sachanski (2) had considered that the action of infill in an infill frame could be affected by transmitting two components of forces, normal and shear, at a finite number of connecting joints, along the frame/infill interface. He had suggested a theoretical solution considering it as a plane stress problem. Current trends of research on infill frame analysis are mostly finite element oriented. The methods based on finite element approaches are relatively more superior to the other known methods of analysis as they are capable of handling more parameters of unknowns. Mallick and Severn (3) were amongst the first few researches to propose a method based on finite element concept to analyse infill frames. Using this method, the authors were able to find the points of separation between the frame and the infill as well as stress distribution along the contact intervals, as an integral part of the solution. Slip between the frame and the infill was also considered in the study. Saneinejad (6) had proposed a method for the analysis and design of steel frames with concrete or masonry infill walls subjected to in-plane forces. His method was based on both the data generated from previous experiments and results from a series of non-linear finite element (NLFE) analyses. The method accounts for both elastic and plastic behaviour of infill frames considering the limited ductility of infill materials. The method can be used to predict the strength and stiffness of infill frames as well as the diagonal cracking load. He had demonstrated the method by designing the end frames of a four-storey building.

In the absence of rational proposals, totally acceptable to all kinds of situations, methods based on experimental investigations were also proposed by some researchers. Mainstone (4) had explored the influence of various factors like aspect ratio of frames, frame/infill relative strengths etc., likely to have major influence on contribution of infill walls towards resisting lateral loads in multi-bay multistorey framed buildings. Barua and Mallik (5) had proposed an approach summarising the test results of 21 experiments on reinforced concrete frames infill with brick masonry subjected to lateral loads. The tests were performed on prototype structures.

\section{METHOD OF STUDY}

The infill frame that is considered for developing the flexibility matrix consists of a one bay one storey frame, extending to the left and right by one span and extending to the top and bottom by one story. The frame members are fixed at their farther ends. The infill frame is assumed to be made-up with three different materials. While RCC is used for modelling the beam and column members (two-node 3$\mathrm{D}$ frame elements), brick masonry is used to model the infill wall panel (four-node, plane stress quadrilateral elements). The interface between the frame and infill wall panel is modelled with cement mortar with two-node 3-D frame elements. Whereas, the cement mortar and brick masonry are treated as linearly elastic, both linearly elastic and nonlinearly elastic material properties are assigned for RCC. The infill wall panel is meshed into approximately $200 \mathrm{~mm} \times 200 \mathrm{~mm}$ sized four-node quadrilateral plane stress elements. The bounding frame members all around the infill have been discretised into a number of frame elements, so as to facilitate the connectivity with the corresponding nodes of infill panel. The elements connecting the nodes on infill panel boundary with nodes on the bounding frame elements are called link elements. Whereas the properties of concrete are taken from IS: 456 and experiments, the properties of mortar and masonry are taken from research papers. A unit force is applied in horizontal direction at the top left hand corner of the infill frame and the linear elastic static analysis module of MSC NASTRAN is run. The displacements corresponding to three degrees of freedom at the top lefthand corner, top right-hand corner, bottom right hand corner and the bottom left-hand corner are recorded in order, which forms the first column of the flexibility matrix. The same process is repeated by applying unit load in turn corresponding to each one degree of freedom and all twelve displacements corresponding to each force application are recorded systematically to form the flexibility matrix of infill frame. Having obtained the flexibility matrix as described above, the matrix is inverted to obtain the stiffness matrix (K). A displacement vector (d) is defined with unit displacements corresponding to each one of the twelve degrees of freedom. The strain energy for the infill frame $(\mathbf{U})$ is calculated by the expression: $1 / 2 * \mathbf{d}^{\mathbf{T}} * \mathbf{K} * \mathbf{d}$.

Modulus of Elasticity of RC members $=29.58 \mathrm{KN} / \mathrm{mm}^{2}$ (for linearly elastic situation)

Modulus of Elasticity of Infill frame $=4.217 \mathrm{KN} / \mathrm{mm}^{2}$ Modulus of Elasticity of cement mortar $=2.958 \mathrm{KN} / \mathrm{mm}^{2}$ The stress strain variation of the RC members: 


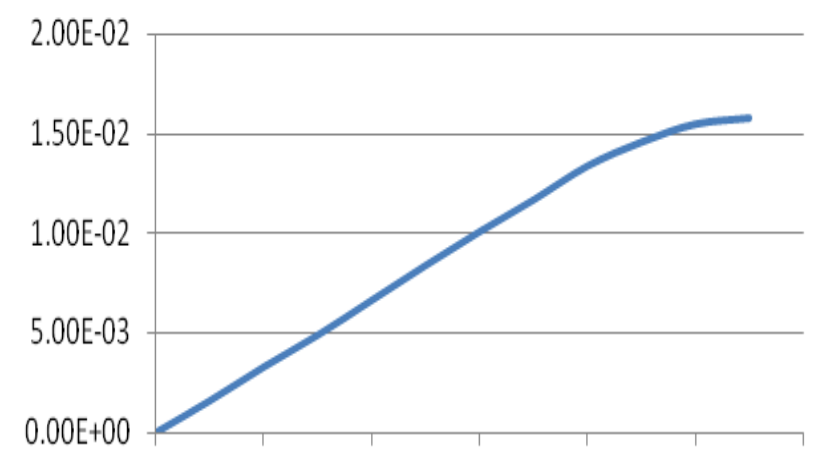

0.00E+001.00E-04 2.00E-04 3.00E-04 4.00E-04 5.00E-04 6.00E-04

Fig-2: Stress vs strain relation of M35 grade concrete
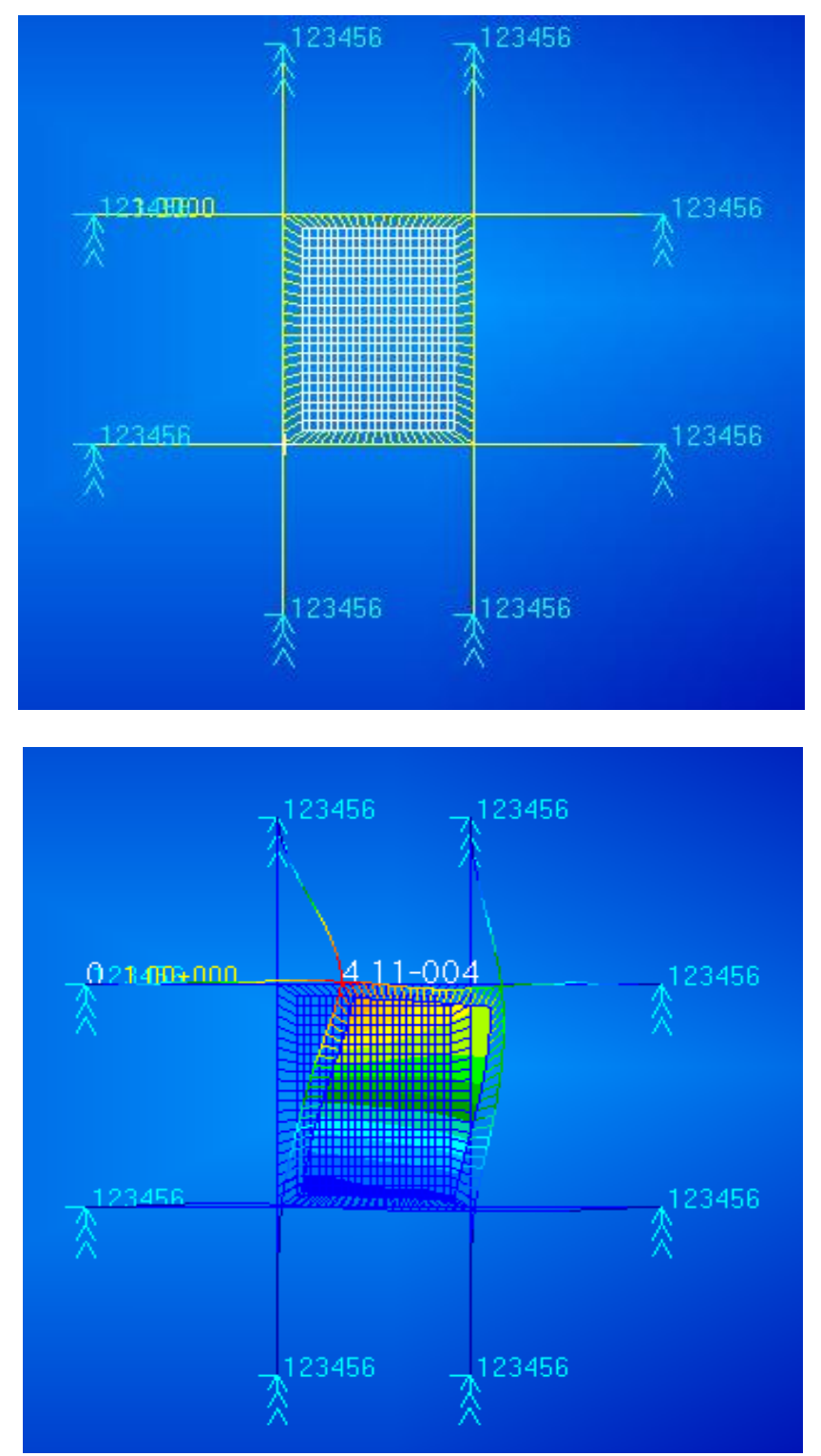

Fig-3: Infill frame with a horizontal force

The infill wall is next replaced with two diagonal struts connecting the opposite corners of frame made in RCC of arbitrary width. The same process as described above is adopted for obtaining the flexibility matrix, stiffness matrix and the strain energy expression. The value of strain energy obtained is compared with strain energy obtained for the frame with infill. The width of strut is altered depending on the difference in magnitudes of the strain energy with strut until such time that both values of strain energies are matching. The aspect ratio of span to storey height is varied and the corresponding equivalent strut widths are determined adopting the same procedure as described above. To make it more widely applicable, the infill frames with door and widow openings have also been analysed and the corresponding strut widths are also evaluated. The data has been tabulated to use it as input training patterns for the BOPN neural net paradigm to be generated.

Since the inputs and outputs for the present problem is continuous type, BOPN Neural Net paradigm is found more appropriate. The set of inputs include the span, the storey height, the area of the door opening(in sq.m), the area of the window opening(in sq.m), the thickness of wall, grade of concrete and linearity/non-linearity of concrete and the output is a single variable of strut width. A five layered neural net architecture is selected to handle the present problem. The hidden layer architecture adopted for the present network is 5-3-3. The learning parameter, momentum parameter, noise and error tolerance are varied to obtain best possible outputs from the trained neural net. The algorithm is so developed that that the weights may either be given are can be generated randomly by ht soft ware. At present, we have a limited eighteen numbers of training patterns with us. After training the net, the stabilised weight matrices are generated by the software. The error that results from the net is expected to be high since the number of training patterns is too small. With more number of samples, a large data of training patterns for strut widths can be generated which would ensure the satisfactory functioning of the neural net paradigm.

Corresponding to the eighteen training patterns generated as described above, the training is under taken with the neural net simulator to obtain the weight matrices for simulation. To test the validity of the training, one of the training patterns with output is fed as test pattern to the simulator. The output obtained from simulation is compared with the target output. Results corresponding to the test pattern after simulation are available from the list of data files trn.dat, tst.dat, weights.dat, results.dat, res_var.dat some of which are enclosed here.

Training data (trn.dat):

\begin{tabular}{|cccccccc|}
\hline 3 & 4 & 0 & 0 & 230 & 35 & 1 & 500 \\
3 & 4 & 2 & 0 & 230 & 35 & 1 & 450 \\
3 & 4 & 0 & 1.2 & 230 & 35 & 1 & 460 \\
4 & 3 & 0 & 0 & 230 & 35 & 1 & 500 \\
4 & 3 & 2 & 0 & 230 & 35 & 1 & 450 \\
4 & 3 & 0 & 1.2 & 230 & 35 & 1 & 470 \\
3 & 3 & 0 & 0 & 230 & 35 & 1 & 460 \\
3 & 3 & 2 & 0 & 230 & 35 & 1 & 350 \\
3 & 3 & 0 & 1.2 & 230 & 35 & 1 & 400 \\
3 & 4 & 0 & 0 & 300 & 35 & 0.8 & 450 \\
3 & 4 & 2 & 0 & 300 & 35 & 0.8 & 400 \\
3 & 4 & 0 & 1.2 & 300 & 35 & 0.8 & 420 \\
\hline
\end{tabular}




\begin{tabular}{|lccccccl|}
\hline 4 & 3 & 0 & 0 & 300 & 35 & 0.8 & 450 \\
4 & 3 & 2 & 0 & 300 & 35 & 0.8 & 400 \\
4 & 3 & 0 & 1.2 & 300 & 35 & 0.8 & 420 \\
3 & 3 & 0 & 0 & 300 & 35 & 0.8 & 400 \\
3 & 3 & 2 & 0 & 300 & 35 & 0.8 & 300 \\
3 & 3 & 0 & 1.2 & 300 & 35 & 0.8 & 350 \\
Test data(tst.dat): & & & \\
4 & 3 & 0 & 1.2 & 300 & 35 & 0.8 \\
Weights data (weights.dat): \\
1 & -0.079162 & 0.102110 & -0.364659 & 0.594364 & -0.762504 \\
1 & -0.959118 & -0.417745 & 0.455096 & 0.054107 & -0.202727 \\
1 & 0.466119 & -0.421608 & -0.151595 & 0.112254 & -0.313836 \\
1 & -0.299514 & -0.780127 & 0.760043 & 0.679868 & -0.499824 \\
1 & 0.943048 & 0.401027 & -0.240561 & 0.260121 & -0.179936 \\
1 & -0.897724 & 0.761995 & -0.603307 & -0.623523 & 0.258422 \\
$1-0.818841$ & -0.057575 & 0.335001 & -0.485943 & -0.242670 \\
2 & -0.091248 & 0.101028 & -0.368218 \\
2 & 0.608460 & -0.775056 & -0.950053 \\
2 & -0.412077 & 0.449551 & 0.068592 \\
2 & -0.199759 & 0.451856 & -0.417452 & \\
2 & -0.156337 & 0.093783 & -0.315795 \\
3 & 0.092060 & 0.301957 & -0.355388 \\
3 & 0.747772 & -0.583023 & -0.963209 \\
3 & -0.325081 & 0.572285 & 0.060961 & \\
4 & 1.313670 & \\
4 & 1.309946 & \\
4 & 0.521057 & & \\
\hline
\end{tabular}

Later the effect of crack widening in the infill panel was shown by the introduction of gap elements wherever the tensile stress was found more than the permissible value. The failure pattern when a horizontal load vertical load and rotation each applied at a time at each corner of the infill panel with gap elements is studied To begin with gap element were introduced in the direction of tensile strength . Subsequently load was incremented $\&$ the increase in the gap was recorded as depicted by the increase in the length of the gap elements. The process of gap widening is demonstrated by figure no:4 to 7 -

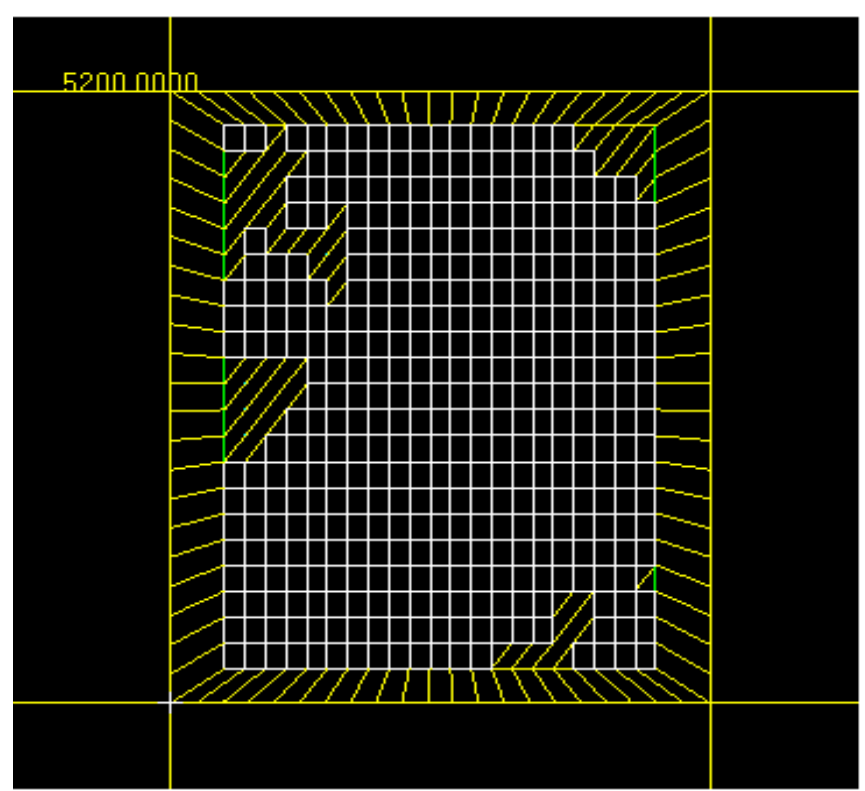

Fig 4 showing the failure patterns for axial load at node 1 .

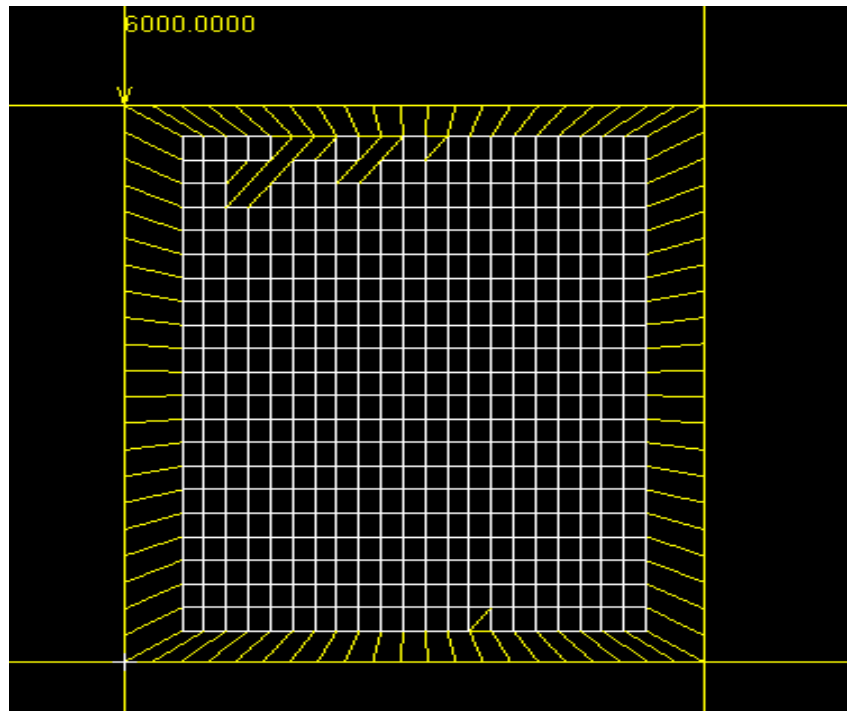

Fig 5 showing the failure patterns for vertical load at node 1.

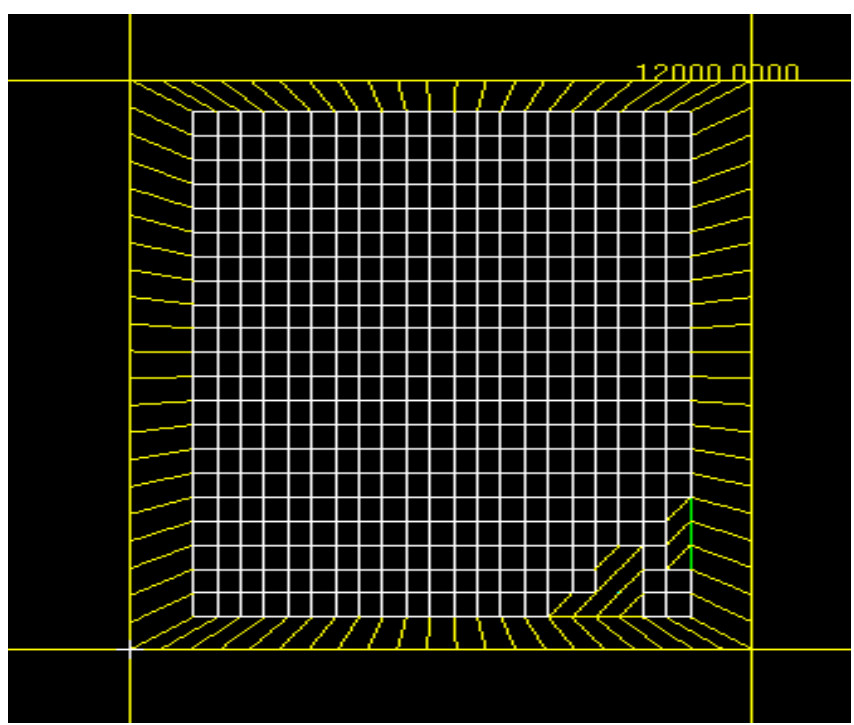

Fig 6 showing the failure patterns for axial load at node 2 .

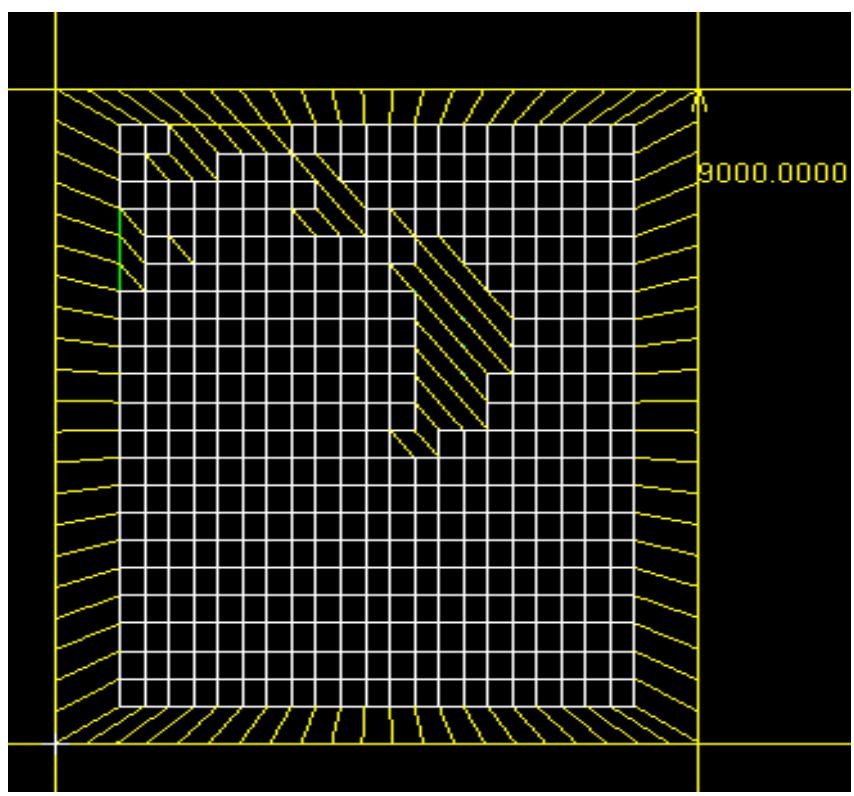

Fig 7 showing the failure patterns for vertical load at node 2. 


\section{RESULTS AND DISCUSSION}

Based on the widths of the equivalent struts listed in the table below, following observations can be made:

[1]. The width of equivalent strut is more when concrete is assumed to be linearly elastic.

[2]. The infill wall offers substantial stiffness even with openings, be it a door or a window.

[3]. The wall stiffness is more when span to height ratio is higher.

[4]. The results obtained from the proposed scale models of 1:3 will be compared with the results obtained using Nastran with gap elements in order to propose suitable penalty factors.

The equivalent strut dimensions for all the frames with and without door /window openings:

\begin{tabular}{|c|c|c|}
\hline & Linear Analysis & $\begin{array}{ll}\text { Non } & \text { Linear } \\
\text { Analysis } & \end{array}$ \\
\hline \multicolumn{3}{|l|}{$\begin{array}{l}\text { For } 3 \mathrm{~m}^{*} 4 \mathrm{~m} \\
\text { frame: }\end{array}$} \\
\hline $\begin{array}{l}\text { With } \\
\text { complete infill }\end{array}$ & $300 \mathrm{~mm} * 500 \mathrm{~mm}$ & $300 \mathrm{~mm} * 450 \mathrm{~mm}$ \\
\hline $\begin{array}{c}\text { With door } \\
\text { opening }\end{array}$ & $300 \mathrm{~mm} * 450 \mathrm{~mm}$ & $300 \mathrm{~mm} * 400 \mathrm{~mm}$ \\
\hline $\begin{array}{l}\text { With window } \\
\text { opening }\end{array}$ & $300 \mathrm{~mm} * 460 \mathrm{~mm}$ & $300 \mathrm{~mm} * 420 \mathrm{~mm}$ \\
\hline \multicolumn{3}{|l|}{$\begin{array}{l}\text { For } 4 m^{*} 3 \mathrm{~m} \\
\text { frame: }\end{array}$} \\
\hline $\begin{array}{l}\text { With } \\
\text { complete infill }\end{array}$ & $300 \mathrm{~mm} * 500 \mathrm{~mm}$ & $300 \mathrm{~mm} * 450 \mathrm{~mm}$ \\
\hline $\begin{array}{c}\text { With door } \\
\text { opening }\end{array}$ & $300 \mathrm{~mm} * 450 \mathrm{~mm}$ & $300 \mathrm{~mm} * 400 \mathrm{~mm}$ \\
\hline $\begin{array}{l}\text { With window } \\
\text { opening }\end{array}$ & $300 \mathrm{~mm} * 470 \mathrm{~mm}$ & $300 \mathrm{~mm} * 420 \mathrm{~mm}$ \\
\hline \multicolumn{3}{|l|}{$\begin{array}{l}\text { For } 3 m * 3 m \\
\text { frame: }\end{array}$} \\
\hline $\begin{array}{l}\text { With } \\
\text { complete infill }\end{array}$ & $300 \mathrm{~mm} * 460 \mathrm{~mm}$ & $300 \mathrm{~mm} * 400 \mathrm{~mm}$ \\
\hline $\begin{array}{c}\text { With door } \\
\text { opening }\end{array}$ & $300 \mathrm{~mm} * 350 \mathrm{~mm}$ & $300 \mathrm{~mm} * 300 \mathrm{~mm}$ \\
\hline $\begin{array}{l}\text { With window } \\
\text { opening }\end{array}$ & $300 \mathrm{~mm} * 400 \mathrm{~mm}$ & $300 \mathrm{~mm} * 350 \mathrm{~mm}$ \\
\hline
\end{tabular}

\section{REFERENCES}

[1]. Smith, B.S., (1962). "Lateral Stiffness of Infill Frames" Journal of Structural Division Proc. ASCE, VOL.88, 183-199.

[2]. Sachanski, S. K., (1960). "Analysis of Earthquake Resistance of Frame Buildings Taking into consideration the Capacity of filling Masonry" Proc. of II World Conf. on Earthquake Engg., III, Japan, 2127 2176.

[3]. Mallick, D.V., \& Severn, R.T., (1967). "The Behaviour of Infill Frames under Static Loading" Proc. ICE, Vol.38, 639-656.

[4]. Mainstone, R.J., (1971). "On the Stiffness and Strength of Infill Frames" Proc. Inst. of Civil Engineers., London, Supplement IV, 57-90 (Paper 7360S).
[5]. Mallick, S. K., \& Barua, H. K., (1977). "Behaviour of One Storey RCC frame Infill with Brickwork under Lateral Loads" Proc. Sixth World Conf. on Earthquake Engg., Vol.3, 3214-3218.

[6]. Saneinejad, A., Hobbs, B., (1995). "Inelastic Design of Infill Frames." ASCE Jn. of Struct. Engrs., Vol.121, No.4,634-650. 